\title{
A comparative study of personality traits 'Form $A$ ' in normal and migraine patients of Meerut City (U.P.), India
}

\author{
Rawat, Rashmi,Tyagi 凶
}

Received: 10.03.2021

Revised: 27.04.2021

Accepted: 15.05.2021

Abstract

In present study, an attempt has been made to estimate the overall effect of migraine on the personality of the subjects and difference in personality traits of migraine and non-migraine patients. The present study was conducted on a sample of 116 migraine patients (of age group 20-60 yrs.). All subjects were residents of Meerut city. Results of high scoring traits show that the following traits like brightness, assertive, venturesome and apprehensive are significantly different among normal male and migraine male subjects.

Key words: Comparative study, personality traits, migraine, patients

\section{Introduction}

The most distinctive quality of any person is his personality. This is the overall pattern, type of behavior, aptitudes, interests, attributes, intellectual abilities and few other distinguishable characteristics. The term migraine refers to periodic hemi cranial throbbing (Burper et al., 1989). The word personality and its root 'person' have long held fascination for students and scholars of language. Headaches often accompanied by nausea and vomiting, which usually begin in childhood, adolescence or early adult life and reach in diminishing number and intensity during advancing years. Headache is so common among the general human population that rare indeed is a person has never suffered one (Cunningham et al., 1987). Migraine is a chronic neurological disorder with many trigger factors. It often starts in childhood or adolescence and it can remain with the patient throughout life. Women are more affected by this disease than men; its prevalence is $12 \%$ of the common population, affecting $18 \%$ to $20 \%$ of women, occurring mainly during their reproductive phases (20 to 50 years old). Migraineurs have been considered nervous, tense and anxious traditionally. Such personality and behavioral pattern are somehow related with migraine headaches. Studies abound in which migraine is also characterized by Author's Address

Department of Psychology, D.A.V. (P.G.) College, Dehradun(U.K.), India

E-mail.: tyagirashmi72@gmail.com such features as less self-confidence, depression, anxiety, less adjustment, fearfulness, low motivation and poor endurance for physical discomforts (Kohler and Kosanic, 1992). The terms 'personality' in English, 'Personalite' in French, and 'personlichkeit' in German. The word 'persona' was used in classical Latin. All scholars were agreeing that the original meaning is mask. In ancient times, persona means other things, including the player behind the mask, i.e., his true qualities having inner and personal features (Cunningham et al., 1987). Price and Blackwall (1980) have compared migraine headache sufferers. A lot of workers have studied on personality traits in classic, tension and migraine patients (HenrykGutt and Rees, 1973; Rees, 1974; Philips, 1976; Rogado et al., 1979). Migraineurs have commonly several environmental triggers of their headaches, such as bright sunlight, barometric pressure change, flickering lights, air quality and odors. Environmental parameters of indoor workplaces and living place are also involve in migraine experience. Awareness and avoidance of trigger factors as a part of the therapeutic medical treatment is used in comprehensive migraine treatment programs. As migraine effects the economy, remediation of correctable environmental triggers can be benefitted for employee presence and productivity among migraineurs. The aim of this study was to make a comparative analysis of 
the personality traits Form 'A' in a sample of normal and migraine patients of Meerut city.

\section{Materials and Methods}

The present study was conducted on a comparative study of personality traits 'Form A' in normal and migraine patients. Subjects consisted of 116 migraine patients of age group 20-60 yrs. All subjects were residents of Meerut city. The present study was conducted during 1994 to 1996 . The sixteen P.F. questionnaires were prepared for the subjects. The 16 P.F. is an objectively scrabble test devised by basic research in psychology to present the complete coverage of personality in a short time.The purposive sampling technique was used to obtain the above-mentioned number of subjects (i.e. migraine patients). All subjects were contacted at different clinics present in Meerut with the help of doctors.

\section{Results and Discussion}

The present study was conducted on a sample of 116 migraine patients (of age group 20-60 yrs.). All subjects were residents of Meerut city. In this study, an attempt has been made to estimate the overall effect of migraine on the personality of the subjects and difference in personality traits of migraine and non-migraine patients (Table-1). Results of high scoring traits show that the following traits are significantly different among migraine and non-migraine subjects.

\section{Trait (B) "More Intelligent"}

From Table 1 it can be seen that the Chi-square value between the two groups is 13.37 , which are significant at 0.05 level the $\mathrm{df}$ being 2 . The subjects in the migraine groups are 23 as compared to 04 in the non migraine groups. This shows that the number of subjects having high intelligence is significantly more in the migraine group than the non-migraine group.

\section{Trait (O) "Apprehensive"}

From Table 1 it can be seen that the Chi-square value between the two groups is 33.06 , which are significant at 0.05 level the df being 2 . The subjects in the migraine groups are 55 as compared to 09 in the non migraine groups. It seems migraine patient are more significantly apprehensive than the nonmigraine group.

\section{Trait (Q3) "Controlled"}

From Table-1, it can be seen that the Chi-square value between the two groups is 7.53 , which are significant at 0.05 level the df being 2 . The subjects in the migraine groups are 09 as compared to 25 in the non migraine groups. This shows that non migraine group have more controlled than the nonmigraine group. Results of high scoring traits show that the following traits like brightness, assertive, venturesome and apprehensive are significantly different among normal male and migraine male subjects.

Table 1: Personality trait (Form A) Normal \& migraine subjects of High \& Low scores

\begin{tabular}{|c|c|c|c|c|c|}
\hline \multicolumn{2}{|c|}{ Traits } & Normal & Migraine & Chi-square values & Significant at 0.05 \\
\hline (B) & $\begin{array}{l}\text { Less Intelligent }(\mathrm{H}) \\
\text { More Intelligent }(\mathrm{L})\end{array}$ & $\begin{array}{l}04 \\
09\end{array}$ & $\begin{array}{l}23 \\
36\end{array}$ & $\begin{array}{l}13.37 \\
16.2\end{array}$ & $"$ \\
\hline (C) & $\begin{array}{l}\text { Emotionally Stable (L) } \\
\text { Affected by feeling (L) }\end{array}$ & 25 & 79 & 28.04 & $"$ \\
\hline (E) & $\begin{array}{l}\text { Assertive (H) } \\
\text { Humble (L) }\end{array}$ & 20 & 05 & 13.89 & $"$ \\
\hline & $\begin{array}{l}\text { Shrewdness (H) } \\
\text { Artlessness (L) }\end{array}$ & 24 & 44 & 5.89 & $”$ \\
\hline & $\begin{array}{l}\text { Apprehensive (H) } \\
\text { Self Assured (L) }\end{array}$ & 09 & 55 & 33.06 & $"$ \\
\hline (Q2) & $\begin{array}{l}\text { Self Sufficient (H) } \\
\text { Group-dependent (L) }\end{array}$ & 11 & 02 & 6.22 & $"$ \\
\hline (Q3) & $\begin{array}{l}\text { Controlled (H) } \\
\text { Undisciplined (L) }\end{array}$ & $\begin{array}{l}25 \\
02\end{array}$ & $\begin{array}{l}09 \\
39\end{array}$ & $\begin{array}{l}7.53 \\
33.39\end{array}$ & $"$ \\
\hline
\end{tabular}

\section{4}

Environment Conservation Journal 
The personality measures showed several significant differences. In this study, we wanted to investigate whether the personality profile of migraine patients differ significantly from normal controls. Kohler and Kosanic (1992) have given same observations that migraineurs have been considered tense, nervous and anxious and also explained that such personality and behavioral traits are somehow connected to the presence of migraine headaches.

Studies abound in which migraine is also characterized by such features as less selfconfidence, depression, anxiety, less adjustment, fearfulness, low motivation and poor endurance for physical discomforts.The administration of the sixteen P.F. Personalities brought out a detailed list of characteristics which seem to be common among migraine personalities. The description so far of the traits and coping pattern of migraine subjects have been discussed in detail. Review of literature supports some of the findings but till date we have not come across any study with all the dimensions taken upon this work. Other studies show that environmental stress like heat cold, crowd and traffic precipitated migraine in female subjects more than male subjects while noise seem to effect male migraineurs more (Tyagi, 2000). Interpersonal stress in women migraineurs and occupational stress in men migraineurs may be typical in the Indian context. The family with its extended family structure may be stressful to women susceptible to migraine. Then work atmosphere particularly in the public sector with its indiscipline, arbitraries and ambiguity may similarly affect male migraineurs. Much work is needed in this area for any definite

\section{References}

Burker, Eileen, Hannay, H., Julia and Halsey, James, H. 1989. Neuropsychological functioning and personality, characteristics of migrainous and non migrainous female college students. Neuropsychology, 3(2): 61-73.

Cunningham, S. J., Mc Grath, P. T., Ferguson, H. B., Homphreys, P. 1987. Personality and behavioural characteristics in Pediatric migraine. Headache, 27(11): 16-20.

Henryk-Gutt, Rita and Rees, W., Linford. 1973. Psychological aspects of migraine. Journal of Psychosomatic Research (Mar), 17(21): 141-153. conclusions to be drawn (Schnarch and Hunter, 1979; Tyagi, 2000; Mokhber, 2013).

\section{Conclusion}

One thousand forty-four women with migraine selected for present study, filled the self-report questionnaire on visual environmental stimuli reported in earlier studies to precipitate or aggravate migraine. Trigger factors are very much frequent in migraine patients, its detection must be studied in detail, so preventive treatment could be more effective. Women are more sensitive and more affected to red wine as a trigger factor than men. Avoiding migraine triggers factors may be helpful in decreasing headache frequency and thus also improve patients' mental health and quality of life. The personality measures present several observable significant differences. As normally reported the migraineurs were high on their intelligence rating. This may be an important factor precipitating a migraine attack since their mind react to any kind of stressful situation and at the same time the results show that they have less control over their actions. Prospective studies are required to determine the extent that external stimuli influence the process of migraine. Different environmental and social trigger factors like light, noise, olfactory and visual stimuli in migraineurs may be minimized by modifying the daily work, home environment and classroom arrangements.

\section{Acknowledgement}

We are thankful to Head, Department of Psychology, D.A.V. (P.G.) College, Dehradun (U.K.), India for providing the necessary facilities.

Kohler, Thomas and Kosanic, Stanimir. 1992. Are persons with migraine characterized by a high degree of ambition, orderliness and rigidity. Pain (Mar), 48(3): 321-323.

Mokhber, N., Ardani, A.R., Beglar, N. Y. and Akbarzadeh, F. 2013. The comparison of personality types in patientswith vascular headache and tension-type headache. Neurology Asia, 18 (4): 377-384.

Philips, Clare. 1976. Headache and personality. Journal of Psychosomatic Research (Mar), 20(6): 535-542.

Price, Kenneth, P. and Blackwall, Scott. 1980. Trait levels of anxiety and psychological responses to stress in Migraineurs and normal controls. Journal of clinical Psychology (Jul), 36(3): 658-660. 


\section{Rawat}

Rees, W., Linford. 1974. Personality and Psychodynamic mechanisms in Migraine. Psychotherapy and Psychosomatics, 23(1-b): 111-121.

Rogado, Alice, Z., Harrisan, Robert, H. and Graham, John, R. 1979. Personality profiles in cluster headache, Migraine and normal controls. Archivosde Neyrobiologia, 37: 227 241.
Schnarch, David, M. and Hunter, John, E. (1979). In: Personality differences between randomly selected Migrainous and non migrainous people. Psychotherapy: Theory, Research \& Practice, 16(3): 297-309.

Tyagi, Rashmi, 2000. In: Ph.D. Thesis "Personality profile of migraine patients and their coping behaviour" submitted to Department of Psychology, C.C.S. University, Meerut. 